\title{
Determination of Six Synthetic Dyes in Sports Drinks by Dispersive Solid-Phase Extraction and HPLC-UV-Vis
}

\author{
Luana Floriano, Lucila C. Ribeiro, Nathália Saibt, Nelson M. G. Bandeira, \\ Osmar D. Prestes and Renato Zanella*
}

\author{
Laboratório de Análise de Resíduos de Pesticidas (LARP), Departamento de Química, \\ Universidade Federal de Santa Maria, 97105-900 Santa Maria-RS, Brazil
}

\begin{abstract}
A simple, fast and efficient method was developed for determination of six synthetic dyes (Tartrazine, Sunset Yellow, Amaranth, Ponceau 4R, Indigo Carmine and Brilliant Blue) in sports drinks using dispersive solid-phase extraction (d-SPE) with the polymeric sorbent Oasis ${ }^{\circledR}$ HLB. Sample preparation using d-SPE permitted to simplify the procedure and use less sorbent in comparison with SPE. The use of a syringe for the elution step make this easier and avoid the use of a manifold. High performance liquid chromatography with UV-Vis detection was employed for quantification. Recovery results, evaluated at $0.5 ; 1.0$ and $1.5 \mathrm{mg} \mathrm{L}^{-1}$, were between 76 and $108 \%$ with relative standard deviation $<18 \%$. The method limit of quantification was $0.5 \mathrm{mg} \mathrm{L}^{-1}$. The developed method was applied to the analysis of commercial sports drinks and the results indicated that all studied samples presented dye levels in conformity with the Brazilian legislation.
\end{abstract}

Keywords: food additives, beverages, d-SPE, sample preparation, liquid chromatography

\section{Introduction}

Sports drinks are specially formulated for people who are undertaking physical activity, being mainly composed by carbohydrates, electrolytes and vitamins. ${ }^{1}$ Additives such as flavors, stabilizers and dyes are commonly used in sports drinks to prevent for spoilage and improve their consumer characteristics and appearance. Nevertheless, this addition must not change the properties of the final product. $^{2}$

Synthetic dyes are a very important class of food additives. ${ }^{3}$ Besides the lower cost of production in relation to dyes of natural origin, synthetic colorants have several advantages such as high stability to light, oxygen and $\mathrm{pH}$, color uniformity and low microbiological contamination. ${ }^{4}$ However, some of these compounds pose adverse health effects (allergy, asthma, hyperactivity, thyroid tumors, etc.), especially when consumed in excess. Thus, their use is strictly controlled around the world. ${ }^{5}$ The list of allowable kinds and concentrations of synthetic dyes is different in each country or region, mainly due to differing opinions regarding the safety of these substances and due to a greater or lesser consumption of artificially colored products. ${ }^{6}$ In Brazil, the maximum limit of colorants in foods including

*e-mail: renato.zanella@ufsm.br sports drinks is established by the National Agency of Sanitary Surveillance (ANVISA), based on international regulations. ${ }^{7}$

In general, high-performance liquid chromatography (HPLC) methods with ultraviolet-visible (UV-Vis), diode-array (DAD) and mass spectrometry detection have been employed for synthetic dyes analysis to ensure food safety. ${ }^{8}$ Regarding sample preparation, solid phase extraction (SPE) is the most commonly used technique prior to instrumental analysis. ${ }^{9}$ Polyamide resin, ${ }^{10,11}$ Strata $^{\mathrm{TM}}-\mathrm{X}-\mathrm{AW},{ }^{12}$ aminopropyl-modified silica, ${ }^{13}$ Oasis ${ }^{\circledR}$ WAX,,${ }^{14,15}$ and Oasis ${ }^{\circledR}$ HLB $^{16}$ are examples of sorbents that have been proposed for determination of colorants.

Despite the wide variety of cartridges commercially available for preparation/purification of foods matrices, SPE steps can be laborious and often requires vacuum or positive-pressure manifold to perform the extraction. ${ }^{17,18}$ Other methods based on the traditional SPE, such as dispersive solid-phase extraction (d-SPE) and magnetic solid-phase extraction (M-SPE), are considered powerful techniques specially for clean-up of food extracts. ${ }^{8}$ However, these techniques were not reported previously for analysis of colorants.

In this context, the aim of the this study was to develop and validate a simple, rapid and effective d-SPE method using the polymeric sorbent Oasis ${ }^{\circledR}$ HLB for the 
determination of six synthetic dyes in sports drinks by HPLC-UV-Vis.

\section{Experimental}

Chemicals, reagents and apparatus

All standards were purchased from Dr. Ehrenstorfer (Germany), with purity between 90.0 and $94.9 \%$. The common names with European Community number (EC) and CAS number, molecular weight (MW), chemical structures, acid dissociation constant $\left(\mathrm{p} K_{\mathrm{a}}\right)$, partition coefficient $(\log \mathrm{P})$, maximum limit of synthetic dyes in drinks and maximum absorbance wavelength $\left(\lambda_{\max }\right)$ of each analyzed compound are shown in Table 1.

Methanol $(\mathrm{MeOH})$ and acetonitrile $(\mathrm{MeCN})$, all HPLC grade, were acquired from Mallinckrodt (USA). Purified water was provided by a Direct-Q ${ }^{\circledR} 3$ UV system (resistivity of $18.2 \mathrm{M} \Omega \mathrm{cm}$ ) from Millipore (France). Ammonium acetate $\left(\mathrm{CH}_{3} \mathrm{COONH}_{4}\right)$ and phosphoric acid solution $\left(\mathrm{H}_{3} \mathrm{PO}_{4}\right) 85 \%$ was supplied from Merck (Germany). Ammonium hydroxide $\left(\mathrm{NH}_{4} \mathrm{OH}\right)$ solution $28-30 \%$ and formic acid 98\% were acquired from Sigma-Aldrich (Germany). SPE cartridges with polymeric sorbent Oasis ${ }^{\circledR}$ HLB (divinylbenzene- $c o-N$-vinylpyrrolidone copolymer; $200 \mathrm{mg} ; 6 \mathrm{~mL}$ ) were purchased from Waters (Ireland).

Sample preparation procedures were performed using analytical balances UX-420H from Shimadzu (Japan) and APX-200 from Denver Instruments (Brazil), vortex shaker (model QL-901) from Biomixer (Brazil), HSW Norm-Ject ${ }^{\circledR}$ 2-part disposable syringes of $3 \mathrm{~mL}$ capacity from Henke Sass Wolf (Germany) and $0.45 \mu \mathrm{m}$ regenerated cellulose filters of $25 \mathrm{~mm}$ from Agilent (China).

\section{Preparation of standard solutions}

Individual stock solutions $\left(1000 \mathrm{mg} \mathrm{L}^{-1}\right)$ were prepared in ultra-purified water, considering the purity of each

Table 1. Common names with $\mathrm{E}$ and CAS number, molecular weight, chemical structure, $\mathrm{p} K_{\mathrm{a}}$, partition coefficient (log P), maximum limit of synthetic dyes in drinks and maximum absorbance wavelength of each studied compound

\begin{tabular}{|c|c|c|c|c|c|c|c|c|}
\hline \multirow{2}{*}{$\begin{array}{l}\text { Compound } \\
\text { (EC/CAS number) }\end{array}$} & \multirow{2}{*}{$\begin{array}{c}\mathrm{MW} / \\
\left(\mathrm{g} \mathrm{mol}^{-1}\right)\end{array}$} & \multirow{2}{*}{ Chemical structure } & \multirow{2}{*}{$\mathrm{p} K_{\mathrm{a}}$} & \multirow{2}{*}{$\log \mathrm{P}$} & \multicolumn{3}{|c|}{ Maximum limit / $\left(\mathrm{mg} \mathrm{L}^{-1}\right)$} & \multirow{2}{*}{$\lambda_{\max } / \mathrm{nm}$} \\
\hline & & & & & EC & Codex & Brazil & \\
\hline $\begin{array}{l}\text { Amaranth } \\
\text { (E 123/915-67-3) }\end{array}$ & 604.47 & & 10.36 & -5.13 & n.a. & n.a. & 50 & 510 \\
\hline $\begin{array}{l}\text { Brilliant Blue } \\
\text { (E 133/3844-45-9) }\end{array}$ & 792.85 & & n.a. & -4.94 & 100 & 100 & 100 & 610 \\
\hline $\begin{array}{l}\text { Indigo Carmine } \\
\text { (E 132/860-22-0) }\end{array}$ & 466.35 & & n.a. & 3.72 & 100 & 100 & 100 & 610 \\
\hline $\begin{array}{l}\text { Ponceau 4R } \\
\text { (E 124/2611-82-7) }\end{array}$ & 604.47 & & 11.24 & & 10 & 50 & 50 & 510 \\
\hline $\begin{array}{l}\text { Sunset Yellow } \\
\text { (E 110/2783-94-0) }\end{array}$ & 452.37 & & 10.36 & -1.18 & 20 & 100 & 100 & 480 \\
\hline $\begin{array}{l}\text { Tartrazine } \\
\text { (E 102/1934-21-0) }\end{array}$ & 534.36 & & 9.40 & -10.17 & 100 & n.a. & 100 & 430 \\
\hline
\end{tabular}

EC: European Community; Codex: Codex Alimentarius; n.a.: not allowed; MW: molecular weight. 
dye standard. From these analytical solutions, a mixture at $10 \mathrm{mg} \mathrm{L}^{-1}$ was prepared in ultra-purified water. These solutions were stored at $\pm 5{ }^{\circ} \mathrm{C}$ in amber flasks. A lemon flavor sport drink, which has no addition of synthetic dyes according to its label and confirmed by the proposed method, was used as blank sample for recovery assays.

\section{Chromatographic conditions}

The chromatographic separation was performed with an HPLC equipped with UV-Vis detector model UltiMate VWD-3400RS from Thermo Scientific (USA) and 9010 gradient mobile-phase pump from Varian (USA). The detector was programmed at a range between 480 and $610 \mathrm{~nm}$. Software Chromeleon 6.8 (Thermo Scientific, USA) was used for data acquisition and processing. The compounds from the mixture were separated in a Microsorb 100-5 C18 column $(250 \times 4.6 \mathrm{~mm}, 5 \mu \mathrm{m}$ particle size $)$ from Varian (Netherlands). Mobile phase consisted of (A) aqueous ammonium acetate solution $0.13 \mathrm{~mol} \mathrm{~L}^{-1}(\mathrm{pH}$ around 7.0) and (B) methanol:acetonitrile (80:20 v/v). The gradient program started at $20 \% \mathrm{~B}$ (held $1 \mathrm{~min}$ ) and increased to reach $50 \% \mathrm{~B}$ in $10 \mathrm{~min}$ and then increase to reach $80 \% \mathrm{~B}$ in $15 \mathrm{~min}$ (held $1 \mathrm{~min}$ ). The gradient return to $20 \% \mathrm{~B}$ at 16 min (held $3 \mathrm{~min}$ ). The total chromatographic run time was $19 \mathrm{~min}$. The optimum flow rate was $1.2 \mathrm{~mL} \mathrm{~min}^{-1}$ whereas the injection volume was $20 \mu \mathrm{L}$.

\section{Sample preparation}

To perform the extraction of dyes from sports drinks, $1 \mathrm{~mL}$ of sample was acidified until $\mathrm{pH} 1-2$ with $\mathrm{H}_{3} \mathrm{PO}_{4}$ $0.1 \mathrm{~mol} \mathrm{~L}^{-1}$ (aqueous solution). The sample was transferred to a $2 \mathrm{~mL}$ Eppendorf with $25 \mathrm{mg}$ of Oasis ${ }^{\circledR}$ HLB sorbent and shaken by vortex for $20 \mathrm{~s}$. All the content was transferred to a $3 \mathrm{~mL}$ HSW Norm-Ject ${ }^{\circledR}$ syringe coupled to a $0.45 \mu \mathrm{m}$ regenerated cellulose filter. The sample was passed through the filter and the filtrate was discarded. The filter was coupled to the syringe and all dyes were eluted by pushing $2 \mathrm{~mL}$ of methanol:ammonium hydroxide (95:5) $(2 \times 1 \mathrm{~mL})$. From the extract, $0.5 \mathrm{~mL}$ was diluted to $1 \mathrm{~mL}$, adjusting the $\mathrm{pH}$ to 7 with an aqueous solution of formic acid 50\% (v/v) for the analysis by HPLC-UV-Vis.

\section{Method validation}

Method validation was performed following the guideline from Inmetro. ${ }^{19}$ To guarantee the method selectivity, chromatographic separation was tested with a standard mixture solution of $1 \mathrm{mg} \mathrm{L}^{-1}$ against blank extracts. Still, dyes were simultaneously detected in four different wavelengths in order to maximize the detector response for the selected dyes. A standard solution at $10 \mathrm{mg} \mathrm{L}^{-1}$ of each dye was submitted to a spectrophotometric analysis to obtain the respective UV-Vis spectra. The wavelengths for HPLC-UV-Vis analysis were chosen based on the higher absorption of each compound. The linearity was evaluated by the coefficient of determination $\left(\mathrm{r}^{2}\right)$ from the analytical curves obtained using external calibration with aqueous solutions containing all the selected dyes at the levels 0.5 ; $0.8 ; 1.2 ; 1.5$ and $2.0 \mathrm{mg} \mathrm{L}^{-1}$. The $\mathrm{pH}$ of the standards were close to neutral and no $\mathrm{pH}$ adjustment was necessary.

The methods limit of detection (LOD) and quantification (LOQ) were calculated considering linearity and signal-to-noise ratio for the lowest calibration level. To evaluate trueness and precision, spiked assays were performed with blank samples at $0.5 ; 1.0$ and $1.5 \mathrm{mg} \mathrm{L}^{-1}$ $(n=6)$. The spiked samples were submitted to the sample preparation and injected into the HPLC-UV-Vis system. By these results, recovery rates were calculated to prove method trueness. The precision was evaluated by calculating the relative standard deviation (RSD) of the six replicates. Inter-day precision was calculated with the six replicates results obtained in different days at $0.5 \mathrm{mg} \mathrm{L}^{-1}$.

\section{Results and Discussion}

\section{Chromatographic analysis}

Figure 1 shows an HPLC-UV-Vis chromatogram of a standard mixture solution at $0.5 \mathrm{mg} \mathrm{L}^{-1}$ where we can notice that fully separation was achieved in the system. The retention time $\left(t_{R}\right)$ values for Tartrazine, Amaranth, Indigo Carmine, Ponceau 4R, Sunset Yellow and Brilliant Blue were $6.9,8.1,8.6,10.3,11.2$ and $16.4 \mathrm{~min}$, respectively.

According to Bento et al., ${ }^{4}$ all dyes elute according to their hydrophobicity and presence of acidic or alkylene groups. The elution order was mainly affected by the presence of azo groups. Azo dyes followed the elution as sequence: Tartrazine, Amaranth, Ponceau 4R and Sunset Yellow, with exception of Indigo Carmine which has polar characteristics due to ketone and amine groups, being the third dye to reach the detector. The last compound to elute was Brilliant Blue due to its lower polar behavior. The good resolution was possible, even with a common C18 column, due to the selection of an adequate gradient of the mobile phase. The final solution extract was diluted with water. At first, no $\mathrm{pH}$ corretion was applied leading to an alkalyne solution with $\mathrm{pH}$ around 11 due to the presence of $\mathrm{NH}_{4} \mathrm{OH}$ in the elution solution. The intensity of peaks at alkalyne condition was poor and peaks were broad. Therefore, the addition of fosforic acid for $\mathrm{pH}$ correction 

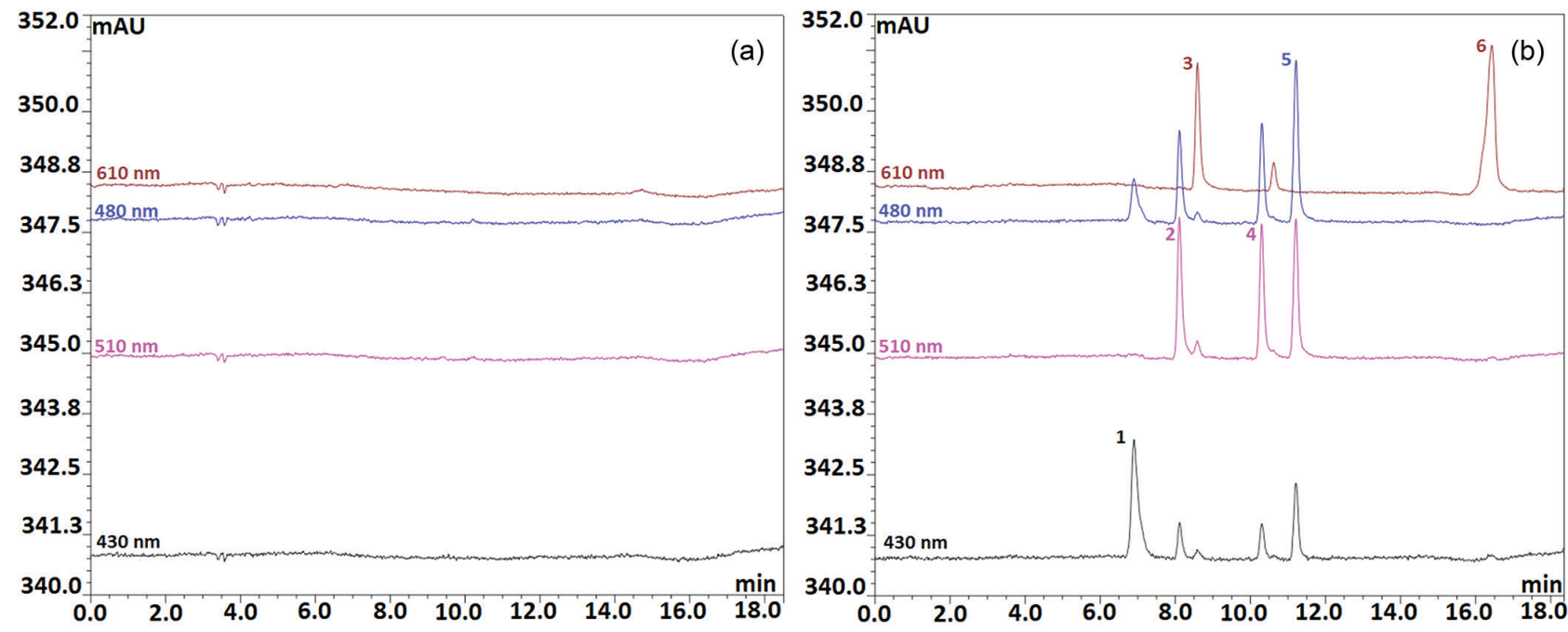

Figure 1. HPLC-UV-Vis chromatograms of (a) a sport drink blank sample and (b) the same blank sample spiked at the LOQ $\left(0.5 \mathrm{mg} \mathrm{L}^{-1}\right)$ for determination of (1) Tartrazine at $430 \mathrm{~nm}$, (2) Amaranth and (4) Ponceau 4R at $510 \mathrm{~nm}$, (3) Indigo Carmine and (6) Brilliant Blue at $610 \mathrm{~nm}$ and (5) Sunset Yellow at $480 \mathrm{~nm}$.

was essential to increase signal-to-noise ratio to responses. Resolution is strongly affected by the mobile phase $\mathrm{pH}$, when a value around 7 was used the dyes remained neutral, according to their $\mathrm{p} K_{\mathrm{a}}$ values, ${ }^{3,20}$ increasing the selectivity and therefore the chromatographic separation. Ammonium acetate is indicated when determination is performed using a UV-Vis detector and proved to be necessary when good resolution and lower running times are required. Although, high concentrations of ammonium acetate can lead to a poor intensity of peaks due to their higher retention in reversed-phase columns. This occurs due to a "salting-out" effect which increases the interactions of dyes with the $\mathrm{C} 18$ column. Ammonium acetate was used as additive at $1 \%$ since the beginning of the study. Methanol was used as organic mobile phase resulting in poor elution strength and resolution. The acetonitrile was gradually added until good peak resolution for all compounds were achieved. The acetonitrile content in the organic mobile phase was also reported as a good additive to allow the elution of dyes with good resolution. ${ }^{3,4,13}$

\section{Development of the extraction method}

Generally, synthetic dyes are added to matrices such as jelly, ice-cream, candies and beverages (soft, energy and sports drinks), which contain a great amount of sugars. Therefore sample preparation is a crucial stage of food dyes analysis. ${ }^{21}$ SPE methods employing aminopropylmodified silica, Oasis ${ }^{\circledR}$ WAX, Oasis ${ }^{\circledR}$ HLB and polyamide sorbents are usually applied for co-extractives removal from foodstuffs and beverages. ${ }^{10,11,13-16}$ However, these techniques required large sample volume and a proper system with vacuum pump and manifold, besides additional steps such as evaporation and reconstitution. Also SPE can be laborious, time-consuming and involve increased consumption of organic solvents. ${ }^{17,22}$ An alternative is the d-SPE method, commonly applied as clean-up step in the QuEChERS (quick, easy, cheap, effective, rugged and safe) approach, ${ }^{23}$ when elution step is not required. ${ }^{24}$ Dyes are often adsorbed in the sorbent, thus elution is an indispensable condition.

In this paper, we present a d-SPE followed by filtration that combine the traditional SPE feature of increase sample concentration with the easy and simple application of d-SPE, without centrifugation or magnetic field separation. Some preliminary assays were carried out employing Oasis ${ }^{\circledR}$ HLB in order to evaluate the best conditions for sample preparation procedure. The Oasis ${ }^{\circledR}$ HLB polymeric sorbent was chosen due to its dual functionality, hydrophilic $N$-vinylpyrrolidone and lipophilic divinylbenzene, that provides an effective extraction of medium to high polarity compounds. ${ }^{25,26}$ First, $25 \mathrm{mg}$ of sorbent were weighed and transferred to an Eppendorf tube. Sample solution was adjusted to a $\mathrm{pH}$ of approximately 1-2 to increase retention of analytes due to the anionic exchange plus Van der Waals' interactions performed by the Oasis ${ }^{\circledR}$ HLB in $\mathrm{pH}<7,{ }^{27}$ until no color remained in the aqueous phase. The homogenization step was evaluated from 10 to $60 \mathrm{~s}$. After $20 \mathrm{~s}$ the dyes were visually retained by the sorbent and the solution was clear and transparent. The content of Eppendorf tube was pushed just once through the filter and the selected dyes remains retained in the sorbent. With all the sorbent in the filter the dyes can now be eluted with a proper solvent, which in this case is methanol:ammonium hydroxide (95:5). Methanol is a suitable solvent for elution and injection on HPLC systems while basic 
conditions are essential to promote anion exchange and increase dyes recovery. ${ }^{28}$ Once the sorbent remained in the filter, any volume of solvent could be used for elution as long as it guarantees complete recovery. In this work, the compounds were eluted twice with $1 \mathrm{~mL}$, leading to a sample dilution. The developed procedure proved to be efficient in removing matrix components by checking qualitatively the absence of carbohydrates in the final extract using Benedict's and Seliwanoff's reagent that indicate the presence of reducing sugars and fructose/ sucrose, respectively. ${ }^{20}$

Comparing the chromatographic response of the standards prepared in purified water with the standards prepared in blank sample, insignificant matrix effect was observed, permitting to select the easiest way that is to use water as solvent for the standard solutions.

\section{Method validation}

As shown in Figure 1, good selectivity was reached as long as all the peaks could be integrated separately from each other with no overlapping or presence of "shoulders". The selection of 4 particular wavelengths for determination of the six dyes also contributed for identification of the analytes. Liquid chromatography with mass spectrometry together with spectrophotometry detection has been applied for determination of dyes by Ma et al.,$^{29}$ Zou et al. ${ }^{30}$ and $\mathrm{Li}$ et al. ${ }^{31}$ However, the use of mass spectrometry significantly increases the costs of analysis. ${ }^{32}$

Table 1 presents the equations of the calibration curve for the six dyes obtained in four absorption wavelengths, indicating that Brilliant Blue is the most sensitive among them, Tartrazine and Sunset Yellow have similar response with higher slope than Amaranth, Ponceau 4R and Indigo Carmine that have lower sensibility. These results are in accordance with Minioti et al. ${ }^{3}$ which had the same profile for calibration curves slope. Analytical curves presented good linearity with $r^{2} \geq 0.99$ for all evaluated dyes.

The limit of quantification was established taking into account the signal-to-noise ratio of the lowest level of calibration curve, with a ratio higher than 10 . Therefore, $0.5 \mathrm{mg} \mathrm{L}^{-1}$ was set as the LOQ. The LOD was estimated by dividing LOQ concentration 3.3 times, resulting in an LOD of $0.15 \mathrm{mg} \mathrm{L}^{-1}$. Limits in this range of concentration are often found in the literature for similar systems..$^{11,13,29}$ Although, lower limit can be reached considering that many studies ${ }^{3,4,10,30,33}$ are able to quantify dyes at concentration lower than $0.1 \mathrm{mg} \mathrm{L}^{-1}$. Due to the 4 times dilution fold of the method, the LOQ represent a concentration of $2 \mathrm{mg} \mathrm{L}^{-1}$ in the samples. The limits reached in this work are more than enough, considering the maximum concentration from 50 to $100 \mathrm{mg} \mathrm{L}^{-1}$ established for studied dyes in sports drinks in Brazilian legislation. ${ }^{7}$

Recovery rates were acquired from blank samples spiked at $0.5 ; 1.0$ and $1.5 \mathrm{mg} \mathrm{L}^{-1}$ to perform intra-day precision and at $0.5 \mathrm{mg} \mathrm{L}^{-1}$ for inter-day precision. The results, presented in Table 2, ranged from 76 to $108 \%$ with RSD from 8 to $18 \%$ for all dyes. According to Bento et al.,$^{4}$ these results are considered acceptables for chromatographic analyses. Recovery rates reported from other works for the same compounds ranged from 66 to $115 \%$ with RSD from 0.3 to $15 \%,{ }^{4,10,11,29,30}$

\section{Application to commercial samples}

The developed method was applied for the analysis of 8 commercial samples of sports drinks purchased from a local market in Santa Maria, RS, Brazil. Tangerine, orange, grape, green grape, passion fruit and mix of fruits sports drinks were evaluated and the results are shown in Table 3. The expected dyes were found below the maximum limit (50-100 $\left.\mathrm{mg} \mathrm{L}^{-1}\right)$ established by

Table 2. Analytical curves information, and results for recovery and precision, in terms of RSD, for intra-day and inter-day assay

\begin{tabular}{|c|c|c|c|c|c|c|c|c|c|c|}
\hline \multirow{3}{*}{ Compound } & \multirow{3}{*}{ Analytical curves equation } & \multirow{3}{*}{$r^{2}$} & \multicolumn{4}{|c|}{$0.5 \mathrm{mg} \mathrm{L}^{-1}$} & \multirow{2}{*}{\multicolumn{2}{|c|}{$\frac{1.0 \mathrm{mg} \mathrm{L}^{-1}}{\text { Intra }}$}} & \multirow{2}{*}{\multicolumn{2}{|c|}{$\frac{1.5 \mathrm{mg} \mathrm{L}^{-1}}{\text { Intra }}$}} \\
\hline & & & \multicolumn{2}{|c|}{ Intra } & \multicolumn{2}{|c|}{ Inter } & & & & \\
\hline & & & $\mathrm{R} / \%$ & $\mathrm{RSD} / \%$ & $\mathrm{R} / \%$ & $\mathrm{RSD} / \%$ & $\mathrm{R} / \%$ & $\mathrm{RSD} / \%$ & $\mathrm{R} / \%$ & $\mathrm{RSD} / \%$ \\
\hline Amaranth & $\mathrm{y}=0.9552 \mathrm{x}-0.0598$ & 0.9917 & 84 & 10 & 79 & 14 & 77 & 10 & 90 & 15 \\
\hline Brilliant Blue & $y=2.1494 x-0.2461$ & 0.9918 & 95 & 14 & 96 & 11 & 90 & 8 & 108 & 18 \\
\hline Indigo Carmine & $y=0.8893 x-0.2461$ & 0.9932 & 82 & 16 & 81 & 16 & 78 & 8 & 86 & 18 \\
\hline Ponceau 4R & $y=0.9412 x-0.0801$ & 0.9964 & 87 & 14 & 87 & 13 & 84 & 8 & 92 & 18 \\
\hline Sunset Yellow & $\mathrm{y}=1.1651 \mathrm{x}-0.0995$ & 0.9919 & 89 & 15 & 86 & 11 & 87 & 8 & 97 & 11 \\
\hline Tartrazine & $\mathrm{y}=1.1781 \mathrm{x}-0.0944$ & 0.9960 & 85 & 15 & 91 & 14 & 76 & 10 & 90 & 11 \\
\hline
\end{tabular}

$r^{2}$ : coefficient of determination; R: recovery; RSD: relative standard deviation. 
ANVISA, ${ }^{7}$ with the exception of Tartrazine in sample S6. However, there was no information about concentration in the label. Perhaps, the concentration of Tartrazine in tangerine sports drinks (S6) was below limit of detection of the proposed method.

Table 3. Results of the dyes analysis in commercial sports drinks samples of different flavors

\begin{tabular}{lccc}
\hline Sample & Flavor & Labeled dye & $\begin{array}{c}\text { Concentration / } \\
\left(\mathrm{mg} \mathrm{L}^{-1}\right)\end{array}$ \\
\hline S1 & tangerine & Tartrazine & $10.61 \pm 0.92$ \\
& Sunset Yellow & $11.49 \pm 1.14$ \\
\hline S2 & grape & Brilliant Blue & $1.99 \pm 0.22$ \\
\hline S3 & mix of fruits & Brilliant Blue & $1.81 \pm 0.19$ \\
\hline S4 & orange & Tartrazine & $11.12 \pm 0.89$ \\
& & Sunset Yellow & $9.06 \pm 0.77$ \\
S5 & green grape & Tartrazine & $1.70 \pm 0.15$ \\
& \multirow{2}{*}{ tangerine } & Brilliant Blue & $<$ LOQ \\
\hline S6 & Tartrazine & n.d. \\
& punset Yellow & $11.84 \pm 0.91$ \\
\hline \multirow{2}{*}{ S7 } & Tartrazine & $2.07 \pm 0.18$ \\
& & Sunset Yellow & $3.79 \pm 0.33$ \\
\hline
\end{tabular}

n.d.: not detected; LOQ: limit of quantification.

\section{Conclusions}

This study describes the application of d-SPE as a sample preparation alternative for a fast determination of synthetic dyes in sports drinks. The extraction procedure employing a polymeric commercial sorbent in dispersive mode proved to be effective for sugars removal. Furthermore, this technique has the advantage of being simpler, easier and cheaper to perform than the conventional SPE technique. The amount of sorbent required for this step is much less than the necessary for the other methods and no manifold is required. The method had good recovery and precision results and can be applied in routine analysis of sports drinks for Tartrazine, Sunset Yellow, Amaranth, Ponceau 4R, Indigo Carmine and Brilliant Blue. To perform the analysis, the $\mathrm{pH}$ and amount of sorbent had to be optimized.

\section{Acknowledgments}

The authors are grateful to the financial support and fellowship grants from the Brazilian agencies CNPq and CAPES.

\section{References}

1. Navarro-Pascual-Ahuir, M.; Lerma-Garcia, M. J.; SimóAlfonso, E. F.; Herrero-Martínez, J. M.; Food Control 2016, 63,110 .

2. Agência Nacional de Vigilância Sanitária (ANVISA); Portaria No. 222, de 24 de Março de 1998. Available at http://portal. anvisa.gov.br/documents/33864/284972/portaria_222. pdf/275752cc-5f68-4b80-97ce-19e95ce1e44b, accessed in September 2017.

3. Minioti, K. S.; Sakellariou, C. F.; Thomaidis, N. S.; Anal. Chim. Acta 2007, 583, 103.

4. Bento, W. A. S.; Lima, B. P.; Paim, A. P. S.; Food Chem. 2015, 183, 154.

5. Sun, H.; Sun, N.; Zhang, J.; Yang, Y.; Food Anal. Methods 2013, 6, 1291.

6. Prado, M. A.; Godoy, H. T.; Aliment. Nutr. 2003, 14, 237.

7. Agência Nacional de Vigilância Sanitária (ANVISA); Resolução da Diretoria Colegiada - RDC No. 5, de 15 de janeiro de 2007. Available at http://www.a3q.com.br/component/ docman/doc_download/7-anvisa-resolucao-rdc-no-5-de-15de-janeiro-de-2007.html, accessed in September 2017.

8. Chen, X.; Zhao, Y.; Shen, H.; Zhou, L.; Pan, S.; Jin, M.; J. Chromatogr. A 2014, 1346, 123.

9. Yamjala, K.; Nainar, M. S.; Ramisetti, N. R.; Food Chem. 2016, 192, 813.

10. Yoshioka, N.; Ichihashi, K.; Talanta 2008, 74, 1408.

11. Bonan, S.; Fedrizzi, G.; Menotta, S.; Elizabetta, C.; Dyes Pigm. 2013, 99, 36.

12. Qi, P.; Lin, Z.; Chen, G.; Xiao, J.; Liang, Z.; Luo, L.; Zhou, J.; Zhang, X.; Food Chem. 2015, 181, 101.

13. Mazdeh, F. Z.; Khorrami, A. R.; Moradi-Khatoonabadi, Z.; EsmaeiliAftabdari, F.; Ardekani, M. R. S.; Moghaddam, G.; Hajimahmoodi, M.; Trop. J. Pharm. Res. 2016, 15, 173.

14. Liu, X.; Yang, J. L.; Li, J. H.; Li, X. L.; Li, J.; Lu, X. Y.; Shen, J. Z.; Wang, Y. W.; Zhang, Z. H.; Food Addit. Contam. 2011, 28, 1315.

15. Yang, Y.; Yin, J.; Shao, B.; Food Addit. Contam. 2011, 28, 1159.

16. Feng, F.; Zhao, Y.; Yong, W.; Sun, L.; Jiang, G.; Chu, X.; J. Chromatogr. B 2011, 879, 1813.

17. Andrade-Eiroa, A.; Canle, M.; Leroy-Cancellieri, V.; Cerdà, V.; TrAC, Trends Anal. Chem. 2016, 80, 641.

18. Jardim, I. C. S. F.; Sci. Chromatogr. 2010, 2, 13.

19. Instituto Nacional de Metrologia, Normalização e Qualidade Industrial (Inmetro); Orientações sobre Validação de Métodos de Ensaios Químicos, DOQ-CGCRE-008, revisão 4, Inmetro: Brasil, 2011.

20. Junior, W. E. F.; Quim. Nova Esc. 2008, 29, 8.

21. Wang, Z.; Zhang, L.; Li, N.; Lei, L.; Shao, M.; Yang, X.; Song, Y.; Yu, A.; Zhang, H.; Qiu, F.; J. Chromatogr. A 2014, $1348,52$. 
22. Khalikova, M. A.; Šatínský, D.; Šmidrkalová, T.; Solich, P.; Talanta 2014, 130, 433.

23. Prestes, O. D.; Adaime, M. B.; Zanella, R.; Sci. Chromatogr. 2011, 3, 51.

24. Muñoz, N. C.; Floriano, L.; Souza, M. P.; Bandeira, N. M. G.; Prestes, O. D.; Zanella, R.; Food Anal. Methods 2017, 10, 320 .

25. Donato, F. F.; Martins, M. L.; Munaretto, J. S.; Prestes, O. D.; Adaime, M. B.;Zanella, R.; J. Braz. Chem. Soc. 2015, 26, 2077.

26. Sabin, G. P.; Prestes, O. D.; Adaime, M. B.; Zanella, R.; J. Braz. Chem. Soc. 2009, 20, 918.

27. Manzo, V.; Honda, L.; Navarro, O.; Ascar, L.; Richter, P.; Talanta 2014, 128, 486.

28. Harp, B. P.; Miranda-Bermudez, E.; Barrows, J. N.; J. Agric. Food Chem. 2013, 61, 3726.
29. Ma, M.; Luo, X.; Chen, B.; Su, S.; Yao, S.; J. Chromatogr. A 2006, 1103, 170 .

30. Zou, T.; He, P.; Yasen, A.; Li, Z.; Food Chem. 2013, 138, 1742.

31. Li, X. Q.; Zhang, Q. H.; Ma, K.; Li, H. M.; Guo, Z.; Food Chem. 2015, 182, 316.

32. Rejczak, T.; Tuzimski, T.; Food Anal. Methods 2017, DOI 10.1007/s12161-017-0905-3.

33. Gonzalez, M.; Gallego, M.; Valcárcel, M.; Anal. Chem. 2003, 75,685 .

Submitted: May 17, 2017

Published online: September 26, 2017

FAPERGS/CAPES has sponsored the publication of this article. 